\title{
Assessing the viability of solar cells
}

To the Editor - Economical solar energy has been chosen by the United States National Academy of Engineering as one of the 14 engineering grand challenges facing humans in the twenty-first century ${ }^{1}$. To evaluate the economic viability of a given photovoltaic cell technology, the photovoltaic community commonly uses a convenient figure of merit known as cost (dollars) per peak watt of electricity generated, $\$ / W_{\text {peak }}$. I would like to explain to readers some reasons why I feel that this term is flawed and alternative figure of merits are required for realistic assessment of this technology.

First, the $\$ / W_{\text {peak }}$ figure of merit is predicated on the assumption that instantaneous peak power, $W_{\text {peak }}$, is the best way to determine photovoltaic cell performance. However, the terrestrial solar spectrum, irradiance and temperature fluctuate strongly from sunrise to sunset and thus so does the actual power output of a photovoltaic cell. The instantaneous peak power, $W_{\text {peak }}$, is typically measured indoors at a temperature of $25^{\circ} \mathrm{C}$ using a lamp to provide a constant perpendicular irradiance of $1,000 \mathrm{~W} \mathrm{~m}^{-2}$ and a spectrum that specifically mimics the atmospheric condition of air mass 1.5 global (AM1.5G). But photovoltaic cells installed around the world rarely operate under precisely these three simultaneous conditions. Therefore, I believe that cells should be tested to determine average power, $W_{\text {avg, }}$, produced over at least an 8-hour period with a fluctuating spectrum, irradiance and temperature mimicking a complete sunrise-to-sunset operating envelope. More to the point, cells and modules should be designed for site-specific application and then tested under typical site-specific conditions.

Second, high-purity photovoltaic-grade semiconductors, which constitute our best photovoltaic cell technologies, are a precious resource that must be conserved. The $\$ / W_{\text {peak }}$ figure of merit provides no direct consideration of material use. Solar photovoltaic (plus solar thermal) energy accounted for only $0.02 \%$ of the net generated electricity in the United States in the year 2008 (ref. 2). If we desire to radically increase our use of solar photovoltaic energy worldwide, a massive amount of active photovoltaic and inactive auxiliary material will be required.

To receive the maximum benefit from our resources (solar energy and semiconductor material), it makes sense to develop photovoltaic cells that produce the highest average power during the entire period between sunrise and sunset (rather than highest instantaneous peak power) with the smallest amount of material $\left(\mathrm{m}^{3}\right)$ at the lowest cost. This gives rise to a new figure of merit for a photovoltaic cell of $W_{\text {avg }} /\left(\mathrm{m}^{3} \$\right)$.

With wide-scale manufacturing and deployment of photovoltaic modules comes not just economic viability but environmental responsibility. One of the primary attributes of photovoltaic energy is that it is an environmentally friendly approach, without the pollution of fossil fuels or the toxicity of nuclear waste. Therefore, it is inappropriate to develop photovoltaic cells containing potent carcinogens such as arsenic and cadmium (for example GaAs and CdTe cells) while marketing this as a green technology. The European Union developed the restriction of hazardous substances (RoHS) directive in July 2006. One of the goals of the RoHS movement is to reduce cadmium ${ }^{3}$. The California Environmental Protection Agency's Office of Environmental Health Hazard Assessment ${ }^{4}$ listed GaAs as a cancer-causing material in August 2008. There are concerns about mercury in fish and lead in consumer electronics. I believe that we should also be concerned about development and large-scale deployment of photovoltaic modules based on serious toxins such as arsenic and cadmium.

Unlike coal and nuclear power plants, which must be located remotely and connected to long-distance electricity transmission lines plagued by resistive losses and high cost, photovoltaic modules are ideally suited for our rooftops and for interfacing with the local electric grid. While flying in and out of various urban airports around the world, a stark observation is that solar photons have travelled $\sim 150$ million kilometres only to find millions of barren rooftops. This situation needs to change.

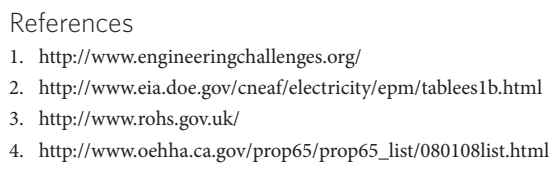

Alexander P. Kirk

Purdue University, School of Materials Engineering, 701 West Stadium Avenue, West Lafayette, Indiana 47907, USA.

e-mail:apkirk@purdue.edu 